\title{
Comparative Study between Ultrasound-Guided Foam Sclerotherapy, Radiofrequency Ablation \& Endo-Venous Laser Ablation in Treatment of Great Saphenous Vein Reflux
}

\author{
AYMAN A. SALEM, M.D.*; WAEL M. ELSHEMY, M.D.*; WALEED A. SOROUR, M.D.* and \\ AHMED M. ABDULKARIM, M.Sc.**
}

The Department of Vascular Surgery, Faculty of Medicine, ZagazigUniversity* and Medical Services Sector, Ministry of Interior**, Egypt

\begin{abstract}
Background: The main goal in the treatment of varicose veins is to reduce the symptoms and complications of chronic venous insufficiency and to improve health related quality of life (QoL) of patients. Surgery has been the standard of care in the treatment of saphenous varicose veins for more than a century.
\end{abstract}

Aim of Study: The aim of this work is to compare between the outcome after UGFS, RFA \& EVLA concerning the treatment of great saphenous vein reflux, regarding success rate, recurrence rate and complications rate.

Subjects and Methods: This study was carried out at the Vascular Surgery Department, Zagazig University Hospitals during the period from August 2016 to August 2018, included a total of 51 treated lower limbs in 39 patients were divided into three different groups: Endovenous Laser Ablation (EVLA group) ( $\mathrm{n}=18$ legs in 13 patients; $1470 \mathrm{~nm}$, continuous mode, radial fiber), Radiofrequency Ablation (RFA group) ( $n=16$ legs in 13 patients) and Ultrasound Guided Foam Sclerotherapy (UGFS group) ( $\mathrm{n}=17$ legs in 13 patients). All patients were subjected to complete clinical examination and laboratory investigations. Post procedure follow-up was done after one week, three month, six months \& one year following treatment and all limbs were assessed clinically and by using DUS.

Results: All the three treatment modalities significantly improved VCSS and QoL as reflected by significant improvements in VCSS and CIVIQ; with no significant differences in the outcome between the groups. The improvements persisted throughout the 2 years and showed that EVLA, RFA and UGFS are efficient treatments with longerterm beneficial effects in patients with GSV varicose veins. This is true even though some patients in the UGFS group developed recanalization of the GSV. UGFS group was significantly longer regarding duration to return to work $(p<0.01)$ than EVLA and RFA group which both had non-significant difference between them.

Correspondence to: Dr. Ayman A. Salem, The Department of Vascular Surgery, Faculty of Medicine, Zagazig University, Egypt
Conclusion: Our study demonstrated that EVLA \& RFA are efficient modalities for the treatment of GSV varicose veins in the medium term. Notinga moderate rate of recanalization after UGFS, it appears that EVLA \& RFA are superior to UGFS regarding clinical recurrence, VCSS and QoL. Postoperative patient comfort and the outcome of EVLA \& RFA in short \& medium-terms are superior to those after UGFS in terms of recanalization \& effective ablation.

Key Words: Endovenous laser ablation - Radiofrequency ablation - Ultrasound guided foam ablation Varicose veins - Reflux.

\section{Introduction}

VARICOSE veins of the lower limbs were defined as dilated subcutaneous veins that are more than $3 \mathrm{~mm}$ in diameter measured in standing. Varicosity can involve the main axial superficial veins; the Great Saphenous Vein (GSV); the Short Saphenous Vein (SSV) or any other superficial vein tributary ofthe lower limbs [1]. The CEAP-classification (06 ) is used for the description of Clinical signs of Chronic Venous Insufficiency (CVI), Etiology (Congenital, primary or secondary), Anatomy (Superficial, deep and perforating vein) and Pathophysiology (Reflux, obstruction or both). The CEAP-classification gives a systematicguide in the clinical investigation of patients. It is an orderly documentation system and gives a synthesis of the phlebological status. It also helps in selecting the appropriate treatment sequence. This classification made diagnosing CVI offered basis for more scientific analysis of management strategies [2]. UGFS is indicated in primary (linear and tortuous) varicose veins, previously treated varicosities and recurrence after surgery (i.e. Neovascularization). Varicosities with small and large diameters could be treated with UGFS but saphenous veins with di- 
ameters of 10 millimeters or more may need frequent treatments and large volumes of foam (up to three sessions and $15 \mathrm{cc}$ of foam). UGFS could be used in patients with severe Chronic Venous Insufficiency (CVI) and may improve healing of ulcers. This technique is used also to treat perforator venous incompetence andcongenital venous malformations [3]. The indications for Radiofrequency ablation (RFA) are the same as EVLA, except that with RFA it is more difficult to treat veins with diameters more than $12 \mathrm{~mm}$. Even though, with ample use of tumescent anesthesia, such veins can be treated successfully. A $5 \mathrm{~F}$. $(1.7 \mathrm{~mm})$ and a $8 \mathrm{~F}$. $(2.7 \mathrm{~mm})$ catheter can be used for varicose veins between 4 and $8 \mathrm{~mm}$ and as large as $12 \mathrm{~mm}$, respectively. The manufacturer introduced a new catheter of unique size that can be used independent of the diameter of the vein. Because of the catheter size $\&$ rigidity, to avoid perforation, extreme care is indicated in treating tortuous and relatively small veins [4]. EVLA can be used in the treatment of insufficient GSV. Because of the rigidity and size of the disposable catheters, linear primary truncal varicosities with diameter of five $\mathrm{mm}$ or more are ideal for EVLA. If thinner fibers are used, EVLA can be used for more tortuous veins suchas the accessory saphenous vein and also perforator veins. In the treatment of recurrent varicosities, care is indicated because introducing the laser may be more difficult with possible risk of inducing embolic events [5]. Both Endovenous Laser Ablation (EVLA) and Radiofrequency Ablation (RFA) are efficient in Great Saphenous Vein (GSV) occlusion on the long term. Lacking long-conducted large trials, the efficacy and reliability of ultrasound guided foam sclerotherapy to treat great saphenous vein-reflux is not affirmed [6].

\section{Subjects and Methods}

\section{I- Patients:}

This study is a prospective Randomized Controlled Clinical Trial (RCT). It was carried out in Vascular Surgery Department, Zagazig University Hospitals after obtaining approval by the Research Ethics Committee, during the period from August 2016 to August 2018. A total of 51 treated limbs in 39 patients were divided into three different groups: Endovenous Laser Ablation (EVLA group) $(\mathrm{n}=18$ legs in 13 patients; $1470 \mathrm{~nm}$, continuous mode, radial fiber), Radiofrequency Ablation (RFA group) ( $\mathrm{n}=16$ legs in 13 patients) and Ultrasound Guided Foam Sclerotherapy (UGFS group) ( $\mathrm{n}=17$ legs in 13 patients).

\section{II- Inclusion criteria:}

1- Primary varicose veins.

2- Age between 18-60 years of age.

3- Sex, no predilection between males \& females.

4- Primary varicose veins.

5- Age between 18-60 years of age.

6- Sex, no predilection between males \& females.

III- Exclusion criteria:

1- Patients with previous Deep Venous Thrombosis (DVT).

2- Patients with congenital venous anomalies.

3- Patients with chronic ischemia (Ankle Brachial Index "ABI" <0.9).

4- Patients with abnormal coagulation profile.

5- Patients with active pulmonary or pleural disease.

IV- Ethical consideration:

1- Approval from Vascular Surgery Department in Zagazig University Hospitals.

2- Approval from institutional review board in Zagazig University Hospitals.

3- Informed consent from the patients or their relatives about the study according to policy of the Zagazig University Hospitals.

4- No harmful procedure will be performed or used for any patients.

V-All patients were subjected to the following:

1- A full history especially history of varicose veins disease.

2- Patient's demographics: Age, sex, smoking, body mass index.

3- Occupation: Job necessitates long standing.

4- Medications history: Allergy to anesthesia, contraceptive pills or usage of anti-coagulants (Warfarin) or antiplatelet drugs (Aspirin, Clopidigrel).

5- Family history: Similar condition, established thrombophilia.

6- Past medical history: History of hypertension, diabetes, cardiac diseases, superficial thrombophlebitis or Deep Vein Thrombosis (DVT).

7- General examination: Including cardiovascular, respiratory \& abdominal examination.

8- Laboratory investigations: Including Complete Blood Count (CBC); Fasting Blood Sugar (FBS) 
and (HbA1C) in diabetic patients; bleeding profile; serum urea and creatinine.

9- Local examination: Examination in the standing patient in a warm room and good light; the size, location, in addition to the distribution of varicose veins; complete pulse examination is accomplished to exclude peripheral arterial disease.

10- Severity assessment: The clinical severity of venous disease was established using CEAP [clinical, etiological, anatomical \& pathological] and VCSS. Further the effect of disease specific quality of life was determined using the CIVIQ:

- In VCSS, each patient was given a score between 0 and 30 according to 10 parameters (pain, varicose veins, edema, pigmentation, inflammation, induration, number of ulcers, duration of ulcers, size of ulcers \& compressive therapy) which are graded 0 to 3 (absent, mild, moderate $\&$ severe).

- In CIVIQ, each patient completed the 20 question Chronic Venous Insufficiency Questionnaire (CIVIQ) quality of life questionnaire after being translated to Arabic. The CIVIQ comprises 20 questions in four quality of life domains (physical, psychological, social \& pain). All questions have a 5 point response category, with higher scores reflecting more severe impairment, and the global scores, were transformed into a scale of 0-100.

\section{1- Duplex ultrasonography:}

- The deep system was evaluated for patency\& presence of abnormal reflux.

- The superficial system was evaluated as regarding the SFJ, GSV, SPJ \& perforators; measuring reflux time \& vein diameter is of great value.

- The presence of retrograde flow lasting $>0.5 \mathrm{~s}$ was considered significant.

- Before surgery, precise mapping (Cartography) was done using duplex-scanning method from the groin to the ankle to highlight tortuous veins, areas of ectasia and incompetent perforators.

\section{VI- Intraoperative performance:}

- The surgical procedure was performed with the patient under spinal anesthesia.

- The venous anatomy was mapped with duplex ultrasound, so the operator review it before beginning the procedure with measuring the size of the vein and noting areas of tortuosity and location of tributaries and perforators.
- Positioning: For GSV ablation; the patient was laid supine, for SSV; patient was laid prone with leg down.

- Anesthesia.

- Tumescent solution $[(5 \mathrm{~mL}$ epinephrine $+5 \mathrm{~mL}$ bicarbonate) and $35 \mathrm{~mL}$ lidocaine $2 \%$ diluted in $500 \mathrm{~mL}$ saline solution or Ringer's lactate)] was administered into the perivenous space under US guidance using a syringe or mechanical infusion pump.

- The preferred site access site for the GSV was just below the knee.

\section{1- Ultrasound-Guided Foam Sclerotherapy protocol (UGFS):}

- The Tessari technique was used to produce the sclerosing foam: [ $2 \mathrm{~mL}$ of purified $2 \%$ Aethoxysklerol and $8 \mathrm{~mL}$ of air (ratio 1:4)] were mixed with 2 syringes connected by a 3-way stopcock. The foam solution was created by a rapid mixing of the air with chemical back and forth between the two syringes. This rapid movement of solution from one syringe to the other was performed 20 times to produce $10 \mathrm{~mL}$ of sclerosing foam.

- The procedure was performed under ultrasound guidance. Patients were positioned in reversed Trendelenburg position to permit better GSV and/or SSV visualization. We accessed the GSV and/or SSV via percutaneous technique using the Seldinger method using a $6 \mathrm{~F} ., 11 \mathrm{~cm}$ long sheath to introduce catheter.

- Positioning of the catheter tip was then reconfirmed before starting the procedure. Continuous pull back was used while we deliver the foam under US guidance.

- Closure of the vein was visualized with duplex ultrasound to identify the foam inside the vein ensure sufficient sclerosis.

- The maximum safest amount used was $20 \mathrm{~mL}$ of foam per session. Patients' legs were elevated for fear of complications of foam embolization such as dyspnea or retinal artery thrombosis.

\section{2- Radiofrequency Ablation protocol (RFA):}

- Access to the varicose vein was obtained with a $6 \mathrm{~F}$. needle under US guidance typically below knee level or distal to the point of reflux.

- The procedures were performed under ultrasound guidance. While patients were positioned in reversed Trendelenburg position; using the Seldinger method; using $8 \mathrm{~F} ., 13 \mathrm{~cm}$ long sheath to introduce the catheter. 
- The catheter was positioned $2 \mathrm{~cm}$ distalto the sapheno-femoral junction under longitudinal US visualization (level of pre-terminal valve).

- A cuff or bandage was used to compress the blood out of the vein.

- Positioning of the catheter tip was then reconfirmed before startingthe procedure. Every pull back was confirmed by a peep from the device that ensured ablation of that $7 \mathrm{~cm}$ of the venous segment, then serial pull backs was used at about $7 \mathrm{~cm} / 30$ seconds.

- The first $7 \mathrm{~cm}$ segment was subjected to 2 sessions of ablations.

- Device details: ClosureFastTM (VNUS) manufactured by $\odot$ Covidien, Dublin, Ireland.

- To prevent skin burns or trauma to the entry site, we stopped when the tip of the catheter fiber was approximately $1-3 \mathrm{~cm}$ above the entry site, which was followed by removal of the fiber and sheath.

- Closure of the vein was visualized with duplex ultrasound to identify an increase in echogenicity of the vein wall to ensure complete ablation.

- Complementary percutaneous ultrasound guided foam injection sclerotherapy using polidocanol (Aethoxysklerol 1 or $2 \%$ ) was done for incompetent perforators and superficial varicosities using the Tessari technique.

\section{3- Endovenous Laser Ablation (EVLA):}

- Venous access was obtained by a puncture with a $6 \mathrm{~F}$. needle under US guidance using the Seldinger method as mentioned before.

- The insufficient GSV was entered at knee level because of ease of access (i.e. large diameter and linear course) with the least risk for nerve injury.

- After entrance to the vein was established, a guidewire was passed through the hollow needle into the vein. Then; the needle was removed \& an introducer sheath was passed over the guidewire.

- The most pivotal step was positioning the echodense tip of the catheter $1-2 \mathrm{~cm}$ distal to the sapheno-femoral junction under longitudinal US visualization (Level of pre-terminal valve) Fig. (1). The wave lengths used in EVLA target deoxygenated hemoglobin and/or water and range of $1470 \mathrm{~nm}$.

- Tumescent anesthesia was warranted. After activation, the laser was pulled back continuously with a pull-back speed of $1-3 \mathrm{~mm} / \mathrm{s}$ according to vein diameter.
- Device details: VenacureTM 1470, Diode Laser, CW, class IV; manufactured by Angiodynamics, US.

- Laser fiber: The procedure with radial firing fiber ensured a more homogenous, precise and controlled energy delivery. Radial emission leads to a homogeneous destruction of the vein wall exclusively, without any risk of damage to surrounding tissues.

- Positioning of the fiber tip was then reconfirmed before starting the procedure. Then, the laser was switched from standby to ready mode and the foot pedal was depressed to deliver energy.

- Power was set at $10 \mathrm{~W}$; the mean energy delivered was ranged from $70-90 \mathrm{~J} / \mathrm{cm}$ for treatment of incompetent GSV.

- Continuous pullback was used while we watched the real-time energy readout on the generator and gauged speed with the $1 \mathrm{~cm}$ marks on the sheath delivering $70-90 \mathrm{~J} / \mathrm{cm}$ according to the vein diameter Fig. (2).

- To prevent skin burns or trauma to the entry site, we stopped treatment by removing the foot from the pedal when the tip of the laser fiber was approximately $1-3 \mathrm{~cm}$ above the entry site, followed by removal of the fiber and sheath.

- Closure of the vein was visualized with duplex ultrasound to identify an increase in echogenicity of the venous wall to ensure complete ablation.

- Complementary percutaneous ultrasound guided foam injection sclerotherapy using polidocanol (Aethoxysklerol 1 or $2 \%$ ) was done as mentioned in RF procedure.

\section{VII- Post-procedural assessment:}

1- Patients were discharged at the same day of the procedure.

2- Compressive bandage or long compressive stocking class II was indicated for 2 weeks.

VIII- Follow-up:

\section{1- Clinical assessment:}

- During each patient's visit a standard set of information were collected.

- Venous Clinical Severity Score (VCSS) classification was determined and compared with the patient's score before the procedure.

- Patients were asked to complete another 20 question Chronic Venous Insufficiency Questionnaire CIVIQ quality of life questionnaire and compared with the patient's score before the procedure. 
- Return to normal activity was asked \& symptoms relief was assessed.

- Patients were asked to complete post-operative assessment data sheets for 30 days assessing for pain by $10 \mathrm{~cm}$ Visual Analogue Scale (VAS).

\section{2- Duplex assessment:}

- Each patient had a follow-up by duplex ultrasound after one week, one month, three month, six months \& one year following treatment for the presence of recurrent varicose veins (short and midterm).

\section{Statistical analysis:}

- Data collected were coded, entered and analyzed using Microsoft Excel software.

- Data were then imported into Statistical Package for the Social Sciences (SPSS version 20.0) software for analysis.

- According to the type of data.

- Qualitative data were represented as numbers and relative percentages.

- Quantitative continuous data were represented by mean \pm SD (standard deviation).

- The following tests were used to test differences for significance.

- Difference and associątion of qualitative variable by Chi square test $\left(\chi^{2}\right)$.

- Differences between quantitative independent groups by ANOVA test.

\section{Results}

The mean age was $30.23 \pm 8.22$ in EVLA group, $32.92 \pm 6.08$ in RFA group and $29.23 \pm 8.12$ in UGFS group; with no significant difference among them. Females were the majority among groups as it were distributed as $53.8 \%$ in EVLA group, $69.2 \%$ in RFA group \& $53.8 \%$ in UGFS group, while males were distributed as $46.2 \%$ in EVLA group, $30.8 \%$ in RFA group \& $46.2 \%$ in UGFS group; with no significant difference among the groups regarding sex. As for BMI, the mean BMI $\left(\mathrm{Kg} / \mathrm{m}^{2}\right)$ was 21.38 \pm 1.55 in EVLA group, $22.07 \pm 0.64$ in RFA group and 22.0 \pm 1.0 in UGFS group with no significant difference among the three studied groups (Table 1) and Fig. (3).

There was non-significant difference whether the lesion was unilateral or bilateral between the three studied groups. Most of RFA group patients were unilateral (Table 2).
There was non-significant difference in distribution of CEAP classification between the three studied groups. Majority of cases were in $\mathrm{C} 4$ category (Table 3 ).

Valve closure time was non-significant among the three studied groups; although $p$-value was $<0.05$, which was a coincidence (Table 4) \& Fig. (4).

UGFS group was significantly longer regarding duration to return to work than EVLA and RFA group which both had non-significant difference between them (Table 5) \& Fig. (5).

All patients had improvement in VAS after the three procedures with Significant Improvement in EVLA \& RFA groups than UGFS group within the 1 st week and after one month post-operative than pre-operative periods Fig. (6).

All patients had improvement in VCSS after the three procedures with a High Significant Improvement in both EVLA \& RFA groups than UGFS group after six months postoperative than pre-operative periods Fig. (7).

Post-operative complications are reported graphically in Fig. (8); we specifically focused on:

1-Hematoma: No hematomas noted among the three studied groups during follow-up.

2- Bruising and phlebitis: Was significantly associated with EVLA and UGFS groups with nonsignificant association regarding bruising; we reported only a single case in RFA group \& we didn't report any case of post-operative pain or hemorrhage (Table 6). All cases improved with conservative management within three weeks.

3- Thermal related injury: One case was reported in EVLA group \& another in RFA group; in the form of mild erythema at a segment along the course of the vein (mainly at the knee) that might be due to insufficient tumescent anesthesia. All cases improved with conservative management within one month.

4- Pigmentation: Occurred in EVLA group \& RFA group in 2 limbs each; along the course of GSV which might be due to vein ablation and persisted for 6 month and occurred in UGFS group in one patient (2 limbs) as a residue to the sclerosing material (Table 7).

5- Paraesthesia: Occurred in EVLA group \& RFA group in 2 limbs each; along the supply of the saphenous nerve, improved within one month and no cases were reported in UGFS group. 
Table (1): Demographic data of the three studied groups (age, BMI and sex distribution).

\begin{tabular}{llllll}
\hline Variant & \multicolumn{1}{c}{ EVLA } & \multicolumn{1}{c}{ RFA } & \multicolumn{1}{c}{ UGFS } & F/ $\chi^{2}$ & $p$ \\
\hline Age & $30.23 \pm 8.22$ & $32.92 \pm 6.08$ & $29.23 \pm 8.12$ & 0.833 & 0.443 \\
BMI & $21.38 \pm 1.55$ & $22.07 \pm 0.64$ & $22.0 \pm 1.0$ & 1.465 & 0.245 \\
Sex: & & & & & \\
- Female: & & & & & \\
$\quad \mathrm{N}$ & 7 & 9 & 7 & 0.84 & 0.65 \\
$\%$ & $53.8 \%$ & $69.2 \%$ & $53.8 \%$ & & \\
- Male: & & & & & \\
$\quad \mathrm{N}$ & 6 & 4 & 6 & & \\
$\%$ & $46.2 \%$ & $30.8 \%$ & $46.2 \%$ & & - \\
\hline Total: & & & 13 & - & - \\
$\mathrm{N}$ & 13 & 13 & $100.0 \%$ & - & - \\
$\%$ & $100.0 \%$ & $100.0 \%$ & &
\end{tabular}

Table (2): Lesion laterality among the three studied groups.

\begin{tabular}{cllllll}
\hline Variant & EVLA & RFA & UGFS & Total & $\chi^{2}$ & $p$ \\
\hline $\begin{array}{c}\text { Bilateral: } \\
\text { N }\end{array}$ & 5 & 3 & 4 & 12 & 1.22 & 0.87 \\
$\%$ & $38.5 \%$ & $23.1 \%$ & $30.8 \%$ & $30.8 \%$ & & \\
Left: & & & & & & \\
$\mathrm{N}$ & 4 & 4 & 5 & 13 & \\
$\%$ & $30.8 \%$ & $30.8 \%$ & $38.5 \%$ & $33.3 \%$ & & \\
Right: & & & & & & \\
$\mathrm{N}$ & 4 & 6 & 4 & 14 & & \\
$\%$ & $30.8 \%$ & $46.2 \%$ & $30.8 \%$ & $35.9 \%$ & & \\
\hline Total: & & & & & & \\
$\mathrm{N}$ & 13 & 13 & 13 & 39 & - \\
$\%$ & $100.0 \%$ & $100.0 \%$ & $100.0 \%$ & $100.0 \%$ & & \\
\hline
\end{tabular}

Table (3): Clinical (CEAP) classification between the three studied groups.

\begin{tabular}{cllllll}
\hline Variant & EVLA & RFA & UGFS & Total & $\chi^{2}$ & $p$ \\
\hline CEAP: & & & & & & \\
$-C_{2:}:$ & & & & & & \\
$\mathrm{N}$ & 0 & 0 & 1 & 1 & 3.3 & 0.509 \\
$\%$ & $0.0 \%$ & $0.0 \%$ & $7.7 \%$ & $2.6 \%$ & & \\
- C3: & & & & & & \\
$\mathrm{N}$ & 2 & 4 & 4 & 10 & & \\
$\%$ & $15.4 \%$ & $30.8 \%$ & $30.8 \%$ & $25.6 \%$ & & \\
- C4: & & & & & & \\
$\mathrm{N}$ & 11 & 9 & 8 & 28 & & \\
$\%$ & $84.6 \%$ & $69.2 \%$ & $61.5 \%$ & $71.8 \%$ & & - \\
\hline Total: & & & & & & \\
$\mathrm{N}$ & 13 & 13 & 13 & 39 & - \\
$\%$ & $100.0 \%$ & $100.0 \%$ & $100.0 \%$ & $100.0 \%$ & - & - \\
\hline
\end{tabular}

Table (4): Pre-operative valve closure time distribution among the three groups.

\begin{tabular}{lccccc}
\hline Variant & EVLA & RFA & UGFS & F & $p$ \\
\hline $\begin{array}{l}\text { V Valve closure } \\
\text { time }\end{array}$ & $0.73 \pm 0.14$ & $0.62 \pm 0.13$ & $0.58 \pm 0.09$ & 4.420 & $0.019 *$ \\
\hline
\end{tabular}

Table (5): Return to work between the three studied groups.

\begin{tabular}{lccccc}
\hline Variant & EVLA & RFA & UGFS & F & $p$ \\
\hline Return to work $9.07 \pm 2.87$ & $8.92 \pm 2.13$ & $15.69 \pm 5.21$ & 13.962 & $0.00^{* *}$
\end{tabular}

Table (6): Post-operative phlebitis \& bruising among the three studied groups.

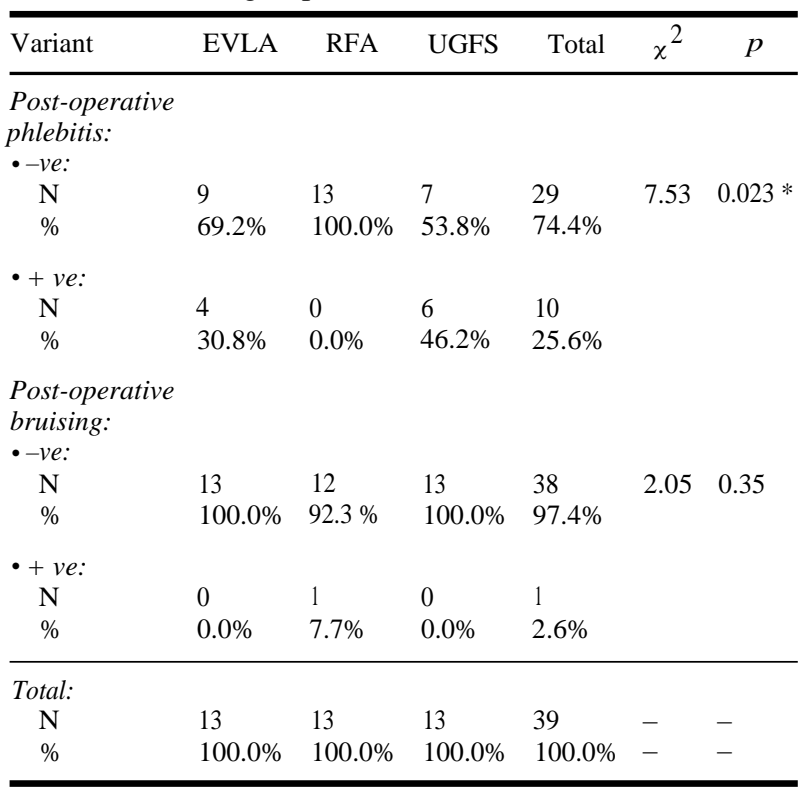

Table (7): Post-operative pigmentation among the three studied groups.

\begin{tabular}{lllllll}
\hline Variant & EVLA & RFA & UGFS & Total & $\chi^{2}$ & $p$ \\
\hline Pigmentation: & & & & & & \\
$\mathrm{N}$ & 12 & 12 & 1 & 5 & 1.22 & 0.87 \\
$\%$ & $15.4 \%$ & $15.4 \%$ & $7.25 \%$ & $38.05 \%$ & & \\
\hline
\end{tabular}

6- DVT: No cases were reported during the 2 years follow-up of the study among the three studied groups.

7- Spinal headache: Occurred in EVLA group in one cases, found in 2 cases of RFA group and increased in UGFS group to 3 cases, which might be due to frequent changing the position of patient during the procedure.

8- Patient satisfaction \& health related quality of life (QOL) [Chronic Venous Insufficiency Questionnaire] (CIVIQ): There was non-significant difference in the CIVIQ between the three studied groups pre-operatively, but 6 months later it was found that there was high significant difference in CIVIQ between EVLA, RFA groups in one hand \& UGFS on the other hand; this is probably due to that 4 cases of UGFS group showed partial occlusion of GSV during follow-up DUS Fig. (9). 


\section{Clinical recurrence:}

Follow-up was done after one week, one month, three month, six months \& one year following treatment; clinically and by using DUS. Partial significant difference was found associated with UGFS group (Table 8); Figs. (10,11).

The need for complementary procedures (reoperation):

There was non-significant difference that required reoperations or complementary procedures; except in 4 cases in UGFS group, in whom required an additional session of UGFS for complete obliteration of GSV (Table 9); Fig. (12). Mean survival from failure in EVLA \& RFA was $24 \pm 0$ months, while in UGFS was $19.5 \pm 2.9$ months Fig. (13).

Table (8): Post-operative duplex results among the three studied groups.

\begin{tabular}{|c|c|c|c|c|c|c|}
\hline Variant & EVLA & RFA & UGFS & Total & $\chi^{2}$ & $p$ \\
\hline \multicolumn{7}{|c|}{$\begin{array}{l}\text { Complete } \\
\text { occlusion: }\end{array}$} \\
\hline $\mathrm{N}$ & 13 & 13 & 9 & 35 & 7.99 & $0.021 *$ \\
\hline$\%$ & $100.0 \%$ & $100.0 \%$ & $69.3 \%$ & $89.8 \%$ & & \\
\hline \multicolumn{7}{|c|}{$\begin{array}{l}\text { Partial } \\
\text { occlusion: }\end{array}$} \\
\hline $\mathrm{N}$ & 0 & 0 & 4 & 4 & & \\
\hline$\%$ & $0.0 \%$ & $0.0 \%$ & $30.7 \%$ & $10.2 \%$ & & \\
\hline \multicolumn{7}{|l|}{ Total: } \\
\hline $\mathrm{N}$ & 13 & 13 & 13 & 39 & - & - \\
\hline$\%$ & $100.0 \%$ & $100.0 \%$ & $100.0 \%$ & $100.0 \%$ & - & - \\
\hline
\end{tabular}

Table (9): Follow-up \& recurrence among the three studied groups.

\begin{tabular}{|c|c|c|c|c|c|c|}
\hline Variant & EVLA & RFA & UGFS & Total & $\chi^{2}$ & $p$ \\
\hline \multicolumn{7}{|c|}{$\begin{array}{l}\text { Recurrence } \\
\text { (short-mid): } \\
\text {--ve: }\end{array}$} \\
\hline $\mathrm{N}$ & 13 & 13 & 9 & 35 & 7.99 & $0.021 *$ \\
\hline$\%$ & $100.0 \%$ & $100.0 \%$ & $69.3 \%$ & $89.8 \%$ & & \\
\hline \multicolumn{7}{|l|}{ - +ve: } \\
\hline $\mathrm{N}$ & 0 & 0 & 4 & 4 & & \\
\hline$\%$ & $0.0 \%$ & $0.0 \%$ & $30.7 \%$ & $10.2 \%$ & & \\
\hline \multirow{3}{*}{\multicolumn{7}{|c|}{$\begin{array}{l}\text { Recurrence } \\
\text { in } 2 \text { years: } \\
\text { - -ve: }\end{array}$}} \\
\hline & & & & & & \\
\hline & & & & & & \\
\hline $\mathrm{N}$ & 13 & 13 & 9 & 35 & 7.99 & $0.021 *$ \\
\hline$\%$ & $100.0 \%$ & $100.0 \%$ & $69.3 \%$ & $89.8 \%$ & & \\
\hline \multicolumn{7}{|l|}{ - +ve: } \\
\hline $\mathrm{N}$ & 0 & 0 & 4 & 4 & & \\
\hline$\%$ & $0.0 \%$ & $0.0 \%$ & $30.7 \%$ & $10.2 \%$ & & \\
\hline \multicolumn{7}{|l|}{ Total: } \\
\hline $\mathrm{N}$ & 13 & 13 & 13 & 39 & & \\
\hline$\%$ & $100.0 \%$ & $100.0 \%$ & $100.0 \%$ & $100.0 \%$ & - & - \\
\hline
\end{tabular}

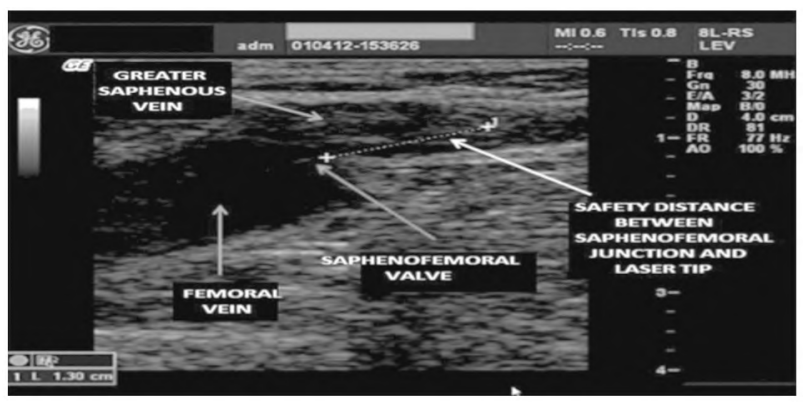

Fig. (1): Placement of the laser tip catheter near SFJ.

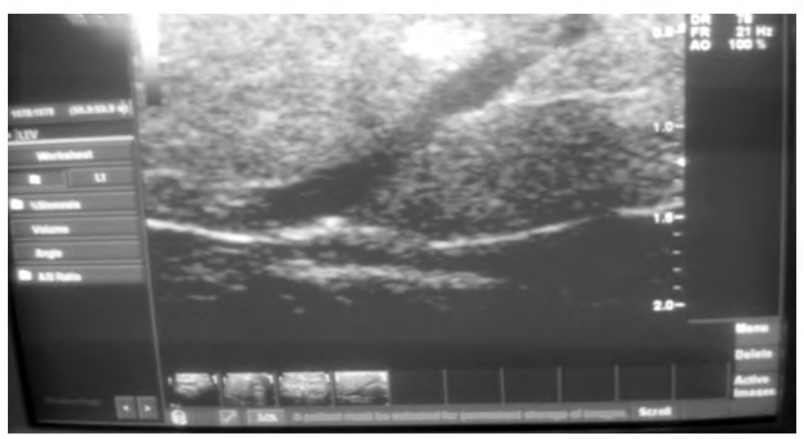

Fig. (2): US of laser catheter after tumescent anesthesia during pull-back.
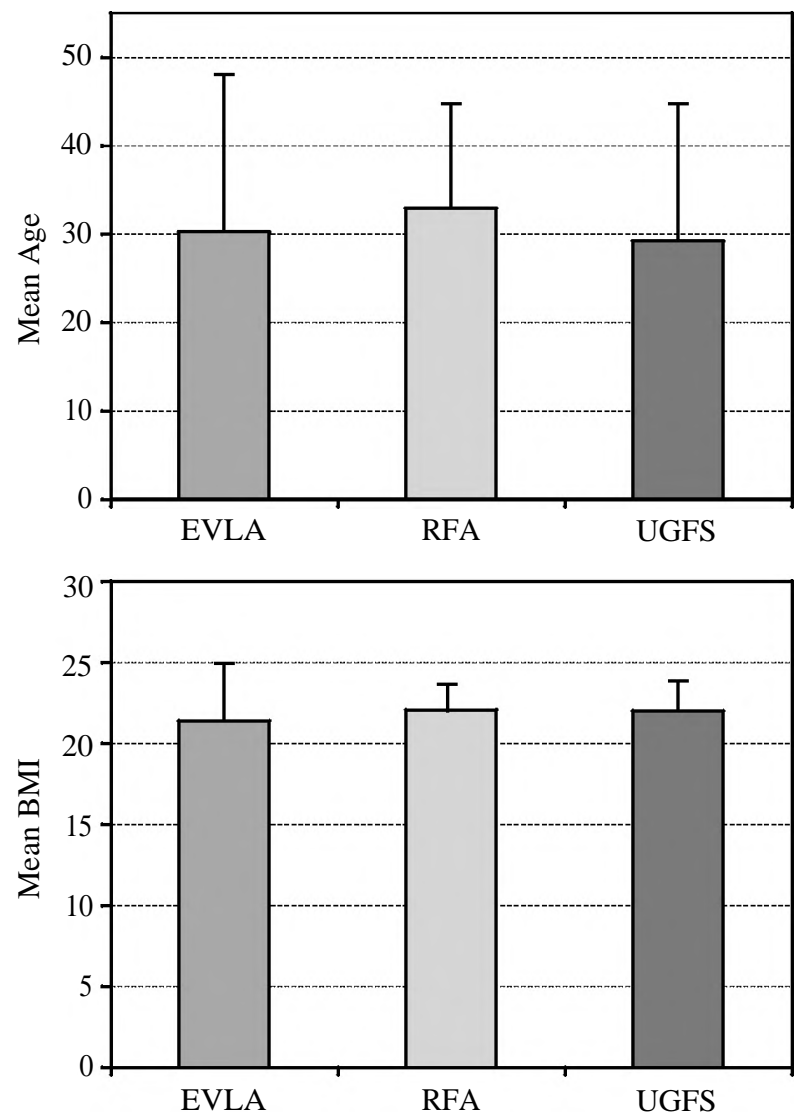

Fig. (3): Demographic data of the three studied groups (age $\&$ BMI distribution). 


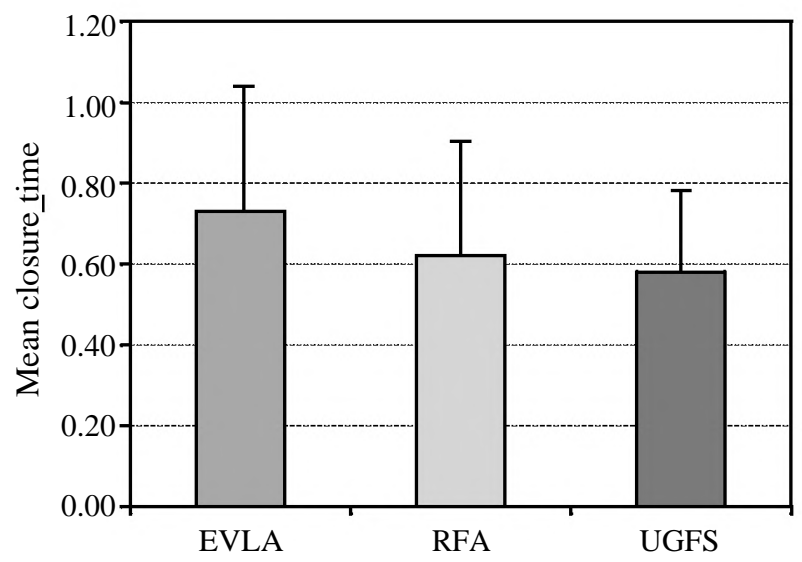

Fig. (4): Mean distribution of valve closure time between the three studied groups.

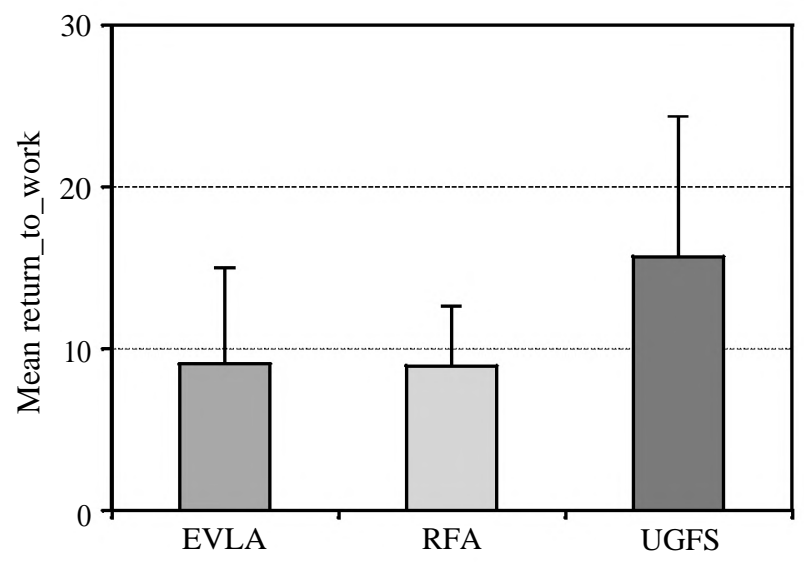

Fig. (5): Return to work between the three studied groups.

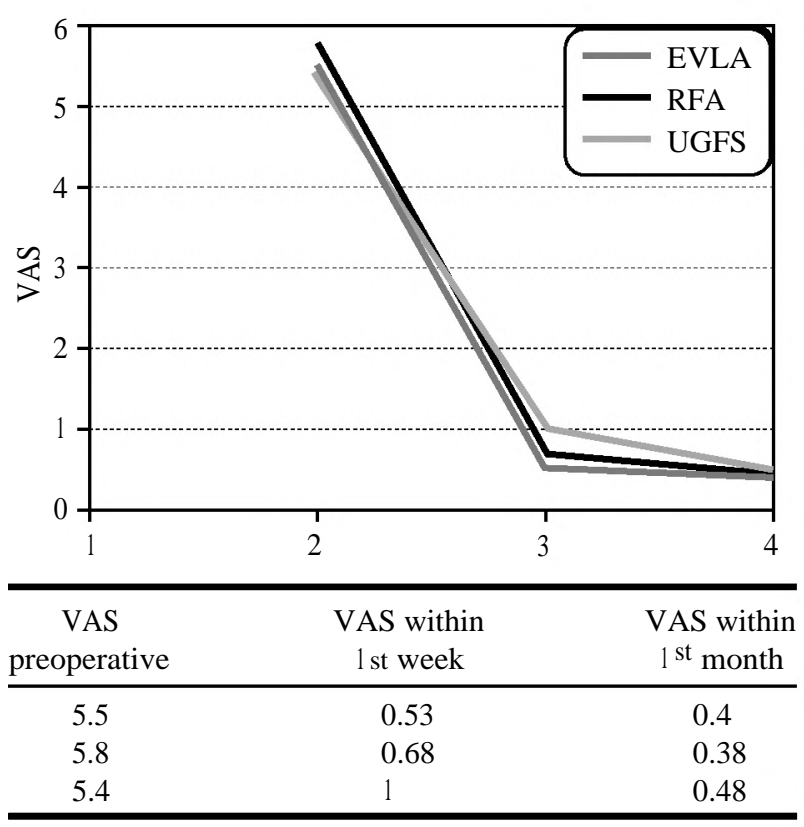

Fig. (6): Visual Analogue Scale (VAS) mean value from preoperative to one month post-operative in the three studied groups.

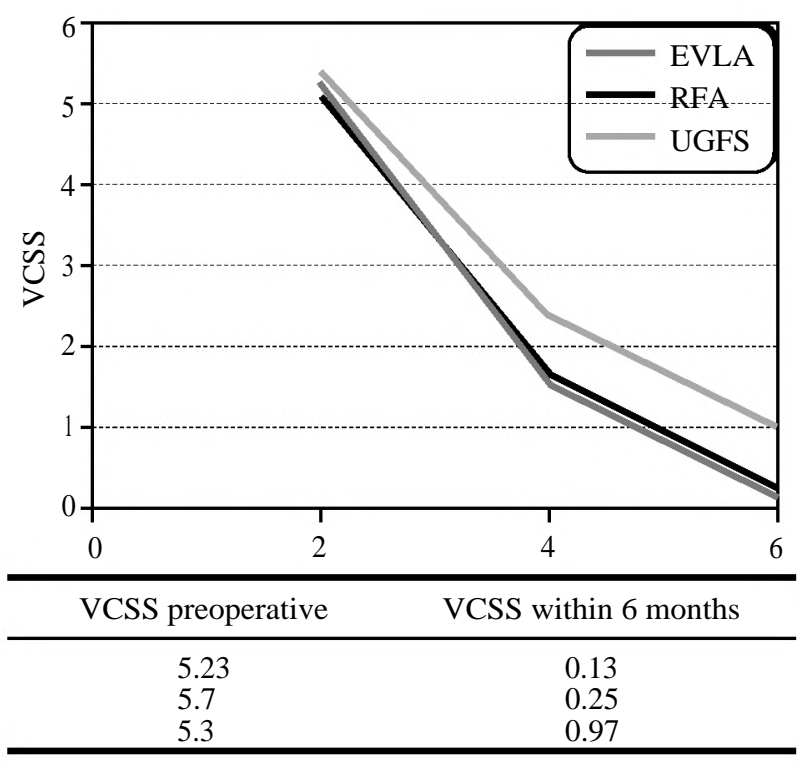

Fig. (7): Venous Clinical Severity Score (VCSS) mean value from pre-operative to 6 months post-operative in the three studied groups.

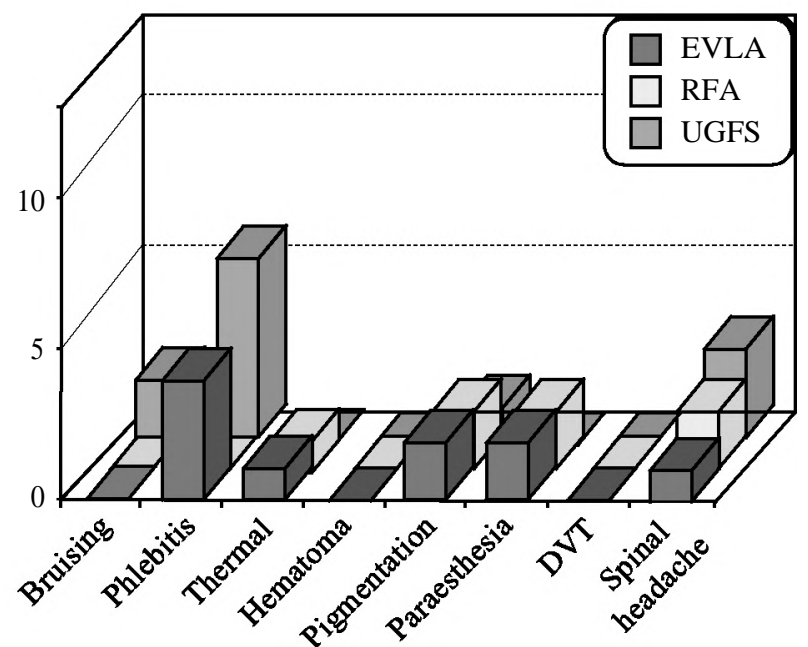

Fig. (8): Post-operative complications.

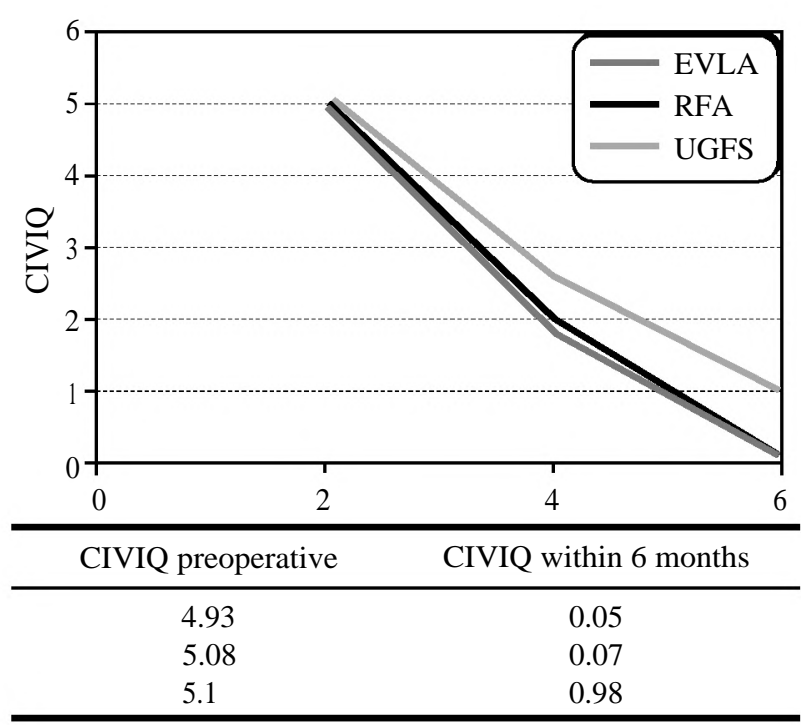

Fig. (9): CIVIQ mean value pre-operative and 6 months postoperative in the 3 studied groups. 

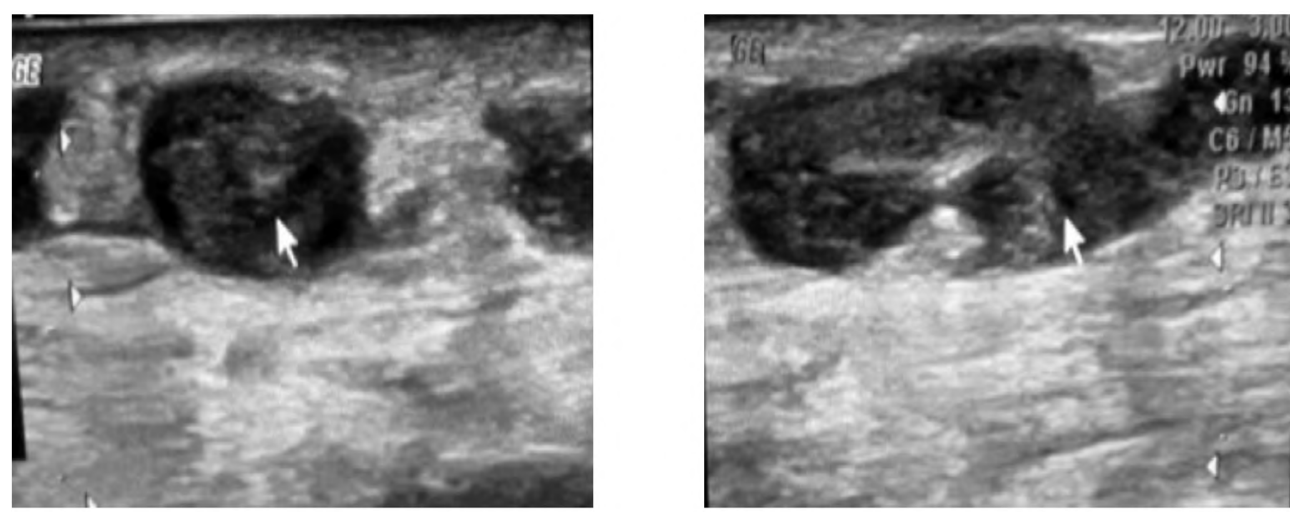

Fig. (10): Intra-operative partial occlusion of GSV following UGFS.

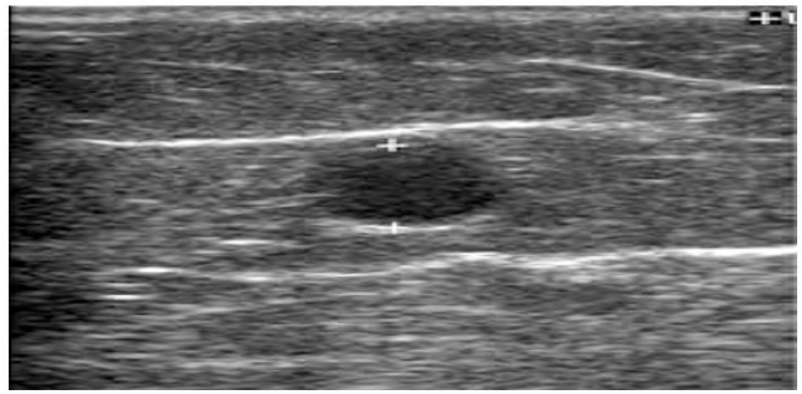

Fig. (11): 2 years follow-up after UGFS shows partial occlusion of GSV (recurrence).

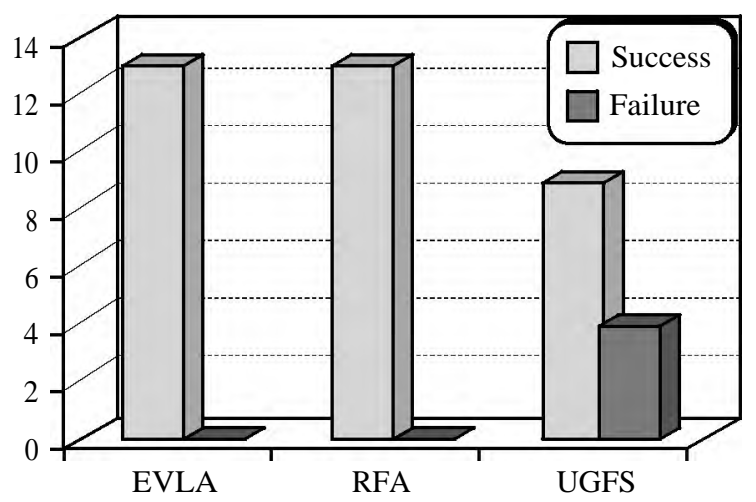

Fig. (12): Success \& failure among the three studied groups.

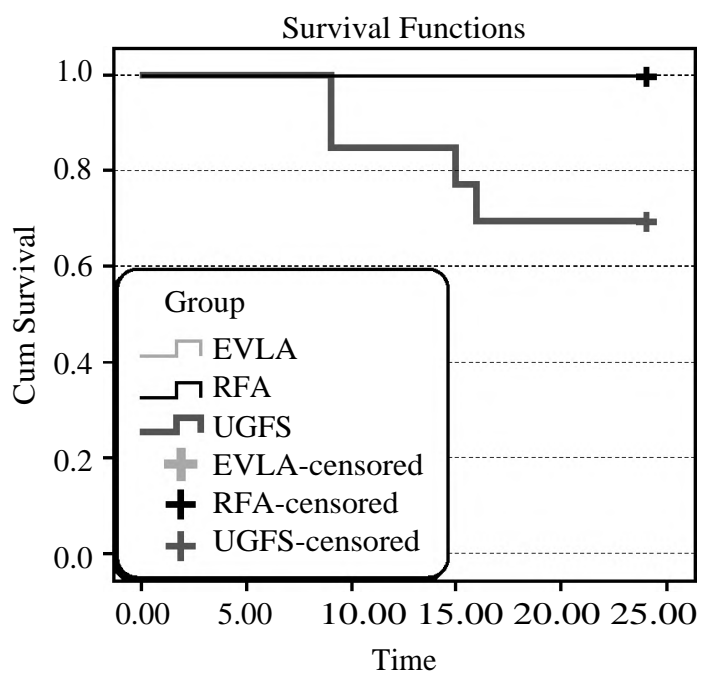

Fig. (13): Kaplan-Meier for failure among the three studied groups (August 2016-August 2018).

\section{Discussion}

Treatment for varicoseve in scan of fersubstantial health related quality of life (QoL) improvements to patients. The market ischaracterized bymany competing modalities and in novation continues toberapid. Established treatments of varicose veins include conservative care (CONS) (Suchas compression stockings), High Ligation surgery (HLS) (usually stripping and ligation of the great and small saphenous veins), Ultrasound GuidedFoam Sclerotherapy (UGFS), Endo Venous Laser Ablation (EVLA) and Radio Frequency Ablation (RFA) [7] . Recent international guidelines for themanagement of varicose veins havebeen issued in U.S and Europe. These guidelines recommend that endovenous thermal ablation (Laser or radiofrequency) should be offered before surgery forthe treatment of great saphenous vein reflux [8]. He et al., 2017 [9]; published a comparison of variousmodalities of treatment of varicose veins oflower limbs. Another study done by Mishra and his colleagues, 2016 [10] ; compared UGFS and RFA in the management of GSV varicosities. In addition, a meta-analysis of studies performed in Japan in the period between 1998 and 2013 was made by the Japanese Society of Phlebology [11]. In our current study, we compared our results with all the above mentioned publications. Regarding to the clinical class; in our study $0 \%$ of patients were in $\mathrm{C}_{2}, 15.4 \%$ as $\mathrm{C}_{3}$ and $84.6 \%$ as $\mathrm{C} 4$ in EVLA group; while $0 \%$ of patients were in $\mathrm{C} 2,30.8 \%$ as $\mathrm{C} 3$ and $69.2 \%$ as $\mathrm{C} 4$ in RFA group and $7.7 \%$ of patients were classified as $\mathrm{C}_{2}, 30.8 \%$ as $\mathrm{C} 3$ and $61.5 \%$ as $\mathrm{C} 4$ in UGFS group. This indicates that patients seek medical advice in late stages of the disease. In the study of Rasmussen et al., 2013 [12]; 95\% of patients were in $\mathrm{C} 2-3$ and $5 \%$ were $\mathrm{C} 4-6$ in EVLA group, $92 \%$ of patients were in $\mathrm{C} 2-3$ and $8 \%$ as $\mathrm{C} 4-6$ in RFA group and $96 \%$ of patients were classified as $\mathrm{C} 2-3$ and $4 \%$ as $\mathrm{C} 4-6$ in UGFS group; this indicates that patients seek medical 
advice in early stages in other countries before major complications happen. As regard to vein diameter; in our study the mean vein diameters were distributed as $(10.15 \pm 2.15),(9.61 \pm 3.12)$ and $(9.46 \pm 2.51)$ in EVLA, RFA \& UGFS groups respectively; which were ranged from $(7-18 \mathrm{~mm})$ in EVLA group, (6-17mm) in RFA group and (7$16 \mathrm{~mm}$ ) in UGFS group. Those diameters did not affect the procedures as regard to tortuosity $\&$ vein lengths. Venermo et al., 2016 [13]; reported lower mean vein diameters of $(6.3 \pm 1.1 \mathrm{~mm}),(6.2 \pm 1.0 \mathrm{~mm})$ and $(5.4 \pm 1.3 \mathrm{~mm})$ in EVLA, RFA \& UGFS groups respectively; which were ranged from $(4-8 \mathrm{~mm})$ in EVLA group, (4-9mm) in RFA group and (3-7mm) in UGFS group. This lower mean vein diameter is probably because those patients in these studies early seek medical advice. Navarro et al., 2002 [14] suggested with evidence that clinical signs of disease correlate with GSV vein diameter, with increasing diameter being associated with greater disease severity. On the other hand; Gibson et al., 2012 [15], stated that GSV diameter is a poor surrogate marker for assessing the effect of varicose veins on a patient's QoL; thus, it is inappropriate to use GSV diameter as a sole criterion for determining medical necessity for the treatment of GSVreflux. Further correlations between QoL measures and duplex derived objective findings are warranted. Regarding to the valve closure time; in our study the mean valve closure times were distributed as $(0.73 \pm 0.14),(0.62 \pm 0.13)$ and $(0.58 \pm 0.09)$ in EVLA, RFA \& UGFS groups respectively; which were ranged from (0.5-1.0s) in EVLA group, (0.5-0.9s) in RFA group and (0.5 $0.8 \mathrm{~s})$ in UGFS group. The valve closure times were significantly higher in EVLA group as compared to UGFS \& RFA groups with no significant difference between UGFS \& RFA groups. Darvall et al., 2010 [16]; studied valve closure times in 385 patients' undergone EVA procedures, and the study fulfilled a range of (0.6-1.0s) in EVLA group, (0.6$1.3 \mathrm{~s})$ in RFA group and (0.7-1.4s) in UGFS group. Another study carried out by Blomgren et al., 2011 [17], conducted for valve closure times in 214 patients revealed a range of (0.6-0.9s) in EVLA group, (0.4-1.0s) in RFA group and (0.5-1.2s) in UGFS group. As regard to anesthesia; in our study, all cases in the three studied groups were done by spinal anesthesia with addition of tumescent solution. Spinal headache is a drawback of spinal anesthesia which occurred in 5 cases and can be explained by frequent changing in the position during the procedure. Erzinger et al., 2016 [18] used spinal or epidural anesthesia in all cases and concluded that tumescent solution proved prevention of minor neurological injuries, but didn't have any influence on the rates of bruising or occlusion of the GSV up to 30 days after EVA procedures.

As regard to UGFS, in our study we operated 17 legs in 13 patients with UGFS, with successful obliteration of GSV at follow-up US; 2 patients (3 legs) showed recanalization ( $30.7 \%$ recurrence) at 2 years follow-up and required additional set of intervention. This high rate of recurrence is probably due to small sample size compared to other studies. O'Hare et al., 2008 [19]; reviewed 32 legs 6 months after UGFS (3\% STS foam) for recurrent VV. They found occlusion of treated veins on DUS at 6 months in 23/32 (72\%) and 28/32 (88\%) were satisfied with the results of treatment. Unfortunately, this represented less than $50 \%$ of their treatedcohort and they gave no further information regarding the type of recurrence treated. They also included some patients treated for SSV rather than GSV recurrence. Darvall et al., 2011 [16] ; added further evidence that UGFS is a safe and clinically effective treatment for recurrent GSV. In their study; a primary course of UGFS, comprising oneand infrequently two treatment sessions, leaded to complete eradication of GSV reflux in virtually $100 \%$ of cases. Recanalization at 12 months was superior to that reported after surgery and similar to that observed following other minimally-invasive techniques. Recanalization was easily and successfully treated with a further single UGFS treatment. As regard to RFA, in our study we operated 16 legs in 13 patients, with successful obliteration of GSV at follow-up US over 2 years. No cases required re-intervention during the follow-up period. Abd Al-Rahman and colleagues, 2013 [20]; reported that segmental radiofrequency ablation actually provides high ablation rates in conjunction with a very moderate side effect profile. The advantages of RFA are far greater than its associated risks. The technique was extremely easy to apply, very reliable both in terms of patient's satisfaction and the clinical results. On the other hand, Whiteley et al., 2017 [21] ; reported neovascularization, the most common cause of recurrence, in three patients $(2 \%)$ in his study on fifty-eight patients (91 legs), the origin couldn't be confirmed, but all three patients under went previous traditional surgical procedures before presenting to their study for RFA. Therefore, it is highly unlikely it was theconsequence of RFA, especially considering the low neovascular occurrence within the remaining cohort and the previously published data of the lack of neovascularization after RFA in primary varicose veins as shown by Kianifard et al., 2006 [22]. As regard to EVLA, in our study we operated 18 legs in 13 patients, with successful obliteration of GSV at follow-up US over 2 years. No cases requiredre- 
intervention during the follow-up period. The laser used in our study was Diode laser $1470 \mathrm{~nm}$ in combination with a radial fiber; Rasmussen et al., 2013 [12], Rustempasic et al., 2014 [23], Velicka et al., 2015 [24] and Venermo et al., 2016 [13] ; all used the same wavelength and comparing the results with UGFS \& RFA groups. Recently published report by Hirokawa et al., 2015 [25]; compared a $1470 \mathrm{~nm}$ radial 2 ring fiber with a $980 \mathrm{~nm}$ bare tip fiber for ablation of saphenous veins. Their study indicates a significant difference between bruising and postoperative pain incidents. 14 patients who under went ablation with the $980 \mathrm{~nm}$ bare tip laser experienced post-operative pain, compared to zero from the $1470 \mathrm{~nm}$ radial 2 ring group; 32 events of bruising compared to 4 were recorded among the two groups respectively. Vourliotakis and colleagues, 2018 [26]; reported that the energy required for the ablation of an incompetent vessel segment, depends on its caliber. High wavelength diode laser such as the $1470 \mathrm{~nm}$ require the application of approximately $65-100 \mathrm{~J} / \mathrm{cm}$ to cause completeocclusion and fibrosis of the vein lumen, with technical success rates reaching approximately 90$100 \%$ observed during 1 year follow-up. In our study, power was set at $10 \mathrm{~W}$; the mean energy delivered was ranged from $70-90 \mathrm{~J} / \mathrm{cm}$ for treatment of incompetent GSV. Technical success was 100\%, as demonstrated during 2 years follow-up. Cowpland et al., 2016 [27] reviewed the clinical evidence affecting optimal LEED and determined the different factors that affect the optimal LEED including the vein diameter, the design of the fiber, wavelength of the laser, rate of pullback and mode of laser delivery. On the other hand; Golbasi and his colleagues, 2015 [28] reported treatment failures using an average LEED of $70 \mathrm{~J} / \mathrm{cm}$, with successful treatments employing a mean LEED of no less than $80 \mathrm{~J} / \mathrm{cm}$. A significant relationship between increasing the LEED and the rate of procedure related complications was noted. Increasing the LEED alone in hugely dilated veins is not sufficient to expose all of the vein wall layers to the thermal injury; that is why Elboushi and his colleauges, 2019 [29] applied multiple passes of the fiber guided by US. Studies of Massaki et al., 2013 [30]; and Kansaku et al., 2015 [31]; confirmed that pulsed wave mode delivers sufficient energy without causing excessive carbonization or vein wall perforation in comparison with continuous mode.

As regard to the time to return to normal activities; in our study the mean time (days) was $9.07 \pm$ 2.87 in EVLA group, 8.92 \pm 2.13 in RFA group and $15.69 \pm 5.21$ in UGFS group with a significant difference between UGFS group and the other two studied groups ( $p$-value $<0.001$ ); with an average of 7-14 days in RFA \& EVLA groups, compared to 10-21 days in UGFS group; we found that the decrease in the time to return to normal activities in of RFA \& EVLA groups was due to the early ambulation of the patients, minimal post-operative complications, less post-operative pain, the minimal need for analgesics, the satisfaction of patients due to absence of surgical wounds. This goes in the same direction with the Brittenden et al., 2015 (class study) [32]; and Nandhra et al., 2015 (HELP2 study) [33] ; who both reported median time to return to work to be 7 days in EVLA \& RFAgroups compared to 15 days in UGFS group. Roopram et al., 2013 (VESPA study) [34]; by contrast, asked participants at the two week clinic whether they had returned to work: $3 / 118(2.4 \%)$ people in the EVLA \& RFA groups and 6/57 (11\%) people in the UGFS group had not returned to work within two weeks of the procedure as a result of the intervention they had received. The study authorsreported that "these percentages were significantly different $(p<0.05) "$. As regard to post-operative pain; it was assessed in our study through the Visual Analogue Scale (VAS). All patients had improvement in VAS after the three procedures with a significant improvement in EVLA \& RFA groups than UGFS group within the 1 st week and after one month post-operative than pre-operative periods. As regard to VCSS, in our study; all patients had improvement in VCSS after the three procedures with a significant improvement in both EVLA \& RFA groups than UGFS group after six months post-operative than pre-operative. There was non-significant difference in the VCSS between the three groups pre-operatively, but 6 months post-operatively there was a high significant difference in VCSS in each group. There are some studies which disagree with ours; for example, Asser et al., 2013 [35]; showed significant improvementof VCSS 2 weeks following the UGFS in comparison to pre-intervention VCSS, where $p$ value was $<0.0001$. Also, there wassignificant improvement of VCSS 6 months following the UGFS in comparison to pre intervention VCSS, where $p$-value was $<0.000111$. Additionally, the disagreement continues with Varghese and his colleagues, 2017 [36] ; where they reported significant improvement in VCSS in their patients who had no ulcer and who had low VCSS prior to UGFS. Our argue with them in that; they selected patients with low VCSS in the beginning of their study, also their follow-up was only for 2 months after treatment. Our 2 years follow-up detected a significant improvement in both EVLA group \& RFA group compared to UGFS group after six months post-operative with a high significant 
difference after 6 months between the three studied groups. Our results goes together with the study of De Oliveira and his colleagues, 2018 [37]; who studied 30 cases with UGFS and its impact on the GSV diameter, concluded reflux elimination in 90 days of $(87 \%)$; which is comparable to rates described in our study. As regard to CIVIQ score, in our study all patients had improvement in CIVIQ after the procedures with a significant improvement in EVLA group \& RFA group than UGFS group after 6 months post-operative. There was nonsignificant difference in the CIVIQ between the three studied groups pre-operatively, but 6 months post-operatively it was found that there is a high significant difference in CIVIQ between EVLA, RFA groups in one hand \& UGFS on the other hand; this is probably due to that 4 cases of UGFS group showed partial occlusion of GSV during follow-up DUS. Kalteis et al., 2015 [38] ; also evaluated CIVIQ scores and found significant improvement after treatment for both EVLA (12 points) and RFA (18 points) with no significant difference between the two treatments compared to UGFS. Epstein and his colleagues, 2018 [7]; concluded that endothermal procedures would be cost-effective therapeutic options in adult patients requiring treatment in the upper leg for incompetence of the GSV. As regard to clinical recurrence, in our study follow-up was done after one week, one month, and 3 months of the procedures then every 6 months up to 2 years clinically and by using DUS. Partial significant difference was found associated with UGFS group, where $p$-value was $<0.05$. Van der Velden and his colleagues, 2016 [39] implied several predictors for recanalization after EVA. For the change of QoL 1 year after treatment with EVA, GSV diameter, the type of device used and amount of energy delivered appeared to be the only predictors. However, the performance of each model was unsatisfactory and therefore cannot yet be used in clinical practice. On the other hand; studies of Lattimer and his colleagues, 2013 [40]; on UGFS have reportedaround $75 \%$ success rate at 1 year and $65 \%$ at 5 years in maintaining truncal occlusion when assessedsonologically, while on clinical assessment, the result was comparableto that of endothermal modalities. As regard to the need for complementary procedures, in our study there was non-significant difference or association that required reoperations or complementary procedures; except in 2 cases in UGFS group, whom required additional session of UGFS for complete obliteration of GSV. Mean survival from failure in EVLA \& RFA was $24 \pm 0$ months, while in UGFS was $19.5 \pm 2.9$ months. This agrees with Elboushi and his colleauges, 2019 [29]; who showed good short-term results of EVLA inthe ablation of large-diameter GSV. Using appropriate LEED and multi-pass technique are good tips in improving the occlusion of the vein and inducing fibrosis of the vein wall. They also added that the use of EVLA has to be adynamic process where the surgeoncan change a variety of parameters like energy, pullback speed, multiple passes and the amount of tumescentfluid injected to optimize the final results of the procedure. This should encourage us to change the concept that EVLA is not suitable for varicose veinslarger than $12 \mathrm{~mm}$.

\section{Limitations of the study:}

This study had some limitations. It only included early clinical experiences from a limited number of patients and only had a short-term data. Some interesting conclusions, however, require longterm recurrence rate follow-up. A shortcoming of the study is that it was not blinded. Whereas a study comparing different thermo-ablation modalities may be blinded, it is not possible to blind the treatment for the patient in a study such as ours. Blinding of the observer may be possible, but it is difficult. It should be noted however, that QoL data are based on the patient's own completions of questionnaires. Furthermore, during follow-up visits, the observer would have no access to information of the primary procedure and little recollection of it.

\section{Conclusion:}

Our study demonstrated that EVLA \& RFA are efficient modalities for the treatment of GSV varicose veins in the medium term. Notinga moderate rate of recanalization after UGFS, it appears that EVLA \& RFA are superior to UGFS regarding clinical recurrence, VCSS and QoL. Post-operative patient comfort and the outcome of EVLA \& RFA in short \& medium-terms are superior to those after UGFS in terms of recanalization \& effective ablation. Using of high wavelength laser $(1470 \mathrm{~nm})$ with modified fiber tip (radial emission) with tumescent solution has a crucial role in achieving best results and minimizing the adverse effects. This allows a homogeneous destruction of the vein wall exclusively, without any risk of damage to surrounding tissues, and also successful ablation of large sized vein diameter.

\section{Financial support and sponsorship:}

Nothing to declare.

\section{Conflicts of interest:}

There were no conflicts of interest. 


\section{References}

1- GLOVICZKI P., COMEROTA A.J., DALSING M.C., EKLOF B., GILLESPIE D.L., GLOVICZKI M.L., LOHR J.M., McLAFFERTY R.B., MEISSNER M.H., MURAD M.H., PADBERG F.T., PAPPAS P.J., PASSMAN M.A., RAFFETTO J.D., VASQUEZ M.A. and WAKEFIELD T. W.: The care of patients with varicose veins and associated chronic venous diseases: Clinical practice guidelines of SVS and AVF. Journal of Vascular Surgery, 53 (16S): 248S, 2011.

2- EKLÖF B., RUTHERFORD R.B., BERGAN J.J., CARPENTIER P.H., GLOVICZKI P., KISTNER R.L., MEISSNER M.H., MONETA G.L., MYERS K., PADBERG F.T., PERRIN M., RUCKLEY C.V., SMITH P.C. and WAKEFIELD T.W.: Special communication from the American Venous Forum International Committee for Revision of the CEAP Classification. Revision of the CEAP classification for chronic venous disorders: Consensus statement. International Ad Hoc Committee for Revision of the CEAP Classification, Helsingborg, Sweden. Journal of Vascular Surgery, (40): 1248-52, 2004.

3- MASUDA E.M., KESSLER D.M., LURIE F., PUGGIONI A., KISTNER R.L. and EKLOF B.: The effect of ultrasound-guided sclerotherapy of incompetent perforator veins on venous clinical severity and disability scores. Journal of Vascular Surgery, 43 (3): 551-6; discussion 67, 2006.

4- WEISS R.A. and WEISS M.A.: Controlled radiofrequency endovenous occlusion using a unique radiofrequency catheter under duplex guidance to eliminate saphenous varicose vein reflux: A 2 year follow-up. Dermatologic Surgery, (28): 38-42, 2002.

5- PROEBSTLE T.M. and HERDEMANN S.: Early results and feasibility of incompetent perforator vein ablation by endovenous laser treatment. Dermatologic Surgery, 33 (2): 162-8, 2007.

6- BALINT R., FARICS A., PARTI K., VIZSY L., BATORFI J., MENYHEI G. and BALINT I.B.: Which endovenous ablation method does offer a better long-term technical success in the treatment of the incompetent great saphenous vein? Review. The Royal Society of Medicine Journals, Vol. 109, (4): 127-66, 2016

7- EPSTEIN D., ONIDA S., BOOTUN R., ORTEGA M.O and DAVIES A.H.: Cost-effectiveness of Current and Emerging Treatments of Varicose Veins. Value in health: The journal of the International Society for Pharmacoeconomics and Outcomes Research; Value Heal, 21 (8): 91120, 2018.

8- KEMP N.: A synopsis of current international guidelines and new modalities for the treatment of varicose veins. (AFP) Australian Family Physicians, 46 (4): 229-33, 2017.

9- HE G., ZHENG C., YU M.A. and ZHANG H.: Comparison of ultrasound-guided endovenous laser ablation andradiofrequency for the varicose veins treatment: An updatedmeta-analysis. International Journal of Surgery, 39: 267 75, 2017.

10- MISHRA M.K., SONI R.K., MOHIL R.S. and SINHA A.: Catheter-Directed Foam Sclerotherapy and Radiofrequency Ablation in the Management of Great Saphenous Varicose Veins. Indian Journal of Surgery, 78 (5): $375-$ 81, 2016.
11- SATOKAWA H., YAMAKI T., IWATA H., SAKATA M., SUGANO N., NISHIBE T., MO M., YAMADA N. and iwai T.: Treatment of Primary Varicose Veins in Japan: Japanese Vein Study XVII. Annals of Vascular Diseases, 9 (3): 180-7, 2016.

12- RASMUSSEN L., LAWAETZ M., SERUP J., BJOERN L., VENNITS B., BLEMINGS A. and EKLOF B.: Randomized clinical trial comparing endovenous laser ablation, radiofrequency ablation; foam sclerotherapy and surgical stripping for great saphenous varicose veins with 3 year follow-up. Journal of Vascular Surgery: Venous and Lymphatic Disorders, 1 (4): 349-56, 2013.

13- VENERMO M., SAARINEN J., ESKELINEN E., VÄHÄAHO S., SAARINEN E., RAILO M., UURTO I., SALENIUS J. and ALBÄCK A.: Randomized clinical trial comparing surgery, endovenous laser ablation and ultrasound-guided foam sclerotherapy for the treatment of great saphenous varicose veins. British Journal of Surgery, 103 (11): 1438-44, 2016.

14-NAVARRO T.P., DELIS K.T. and RIBEIRO A.P.: Clinical and hemodynamic significance of the greater saphenous vein diameter in chronic venous insufficiency. Archives of Surgery, 137 (11): 1233-37, 2002.

15- GIBSON K., MEISSNER M. and WRIGHT D.: Great saphenous vein diameter does not correlate with worsening quality of life scores in patients with great saphenous vein incompetence. Journal of Vascular Surgery, 56 (6): 1634-41, 2012.

16- DARVALL K.A.L., BATE G.R., ADAM D.J., SILVERMAN S.H. and BRADBURY A.W.: Duplex Ultrasound Outcomes Following UltrasoundGuided Foam Sclerotherapy of Symptomatic Primary Great Saphenous Varicose Veins. European Journal of Vascular and Endovascular Surgery, 42 (1): 107-14, 2011.

17- BLOMGREN L., JOHANSSON G., EMANUELSSON L., DAHLBERG-AKERMAN A., THERMAENIUS P. and BERGQVIST D.: Late follow-up of a randomized trial of routine duplex imaging before varicose vein surgery. British Journal of Surgery, 98 (8): 1112-16, 2011.

18- ERZINGER F.L., ARAUJO W.J.B, NEJM J.C.S, CARON F.C. and TIMI J.R.R.: Comparative study of great saphenous vein ablation in the thigh, with and without tumescence. Journal of Vascular Brasileiro, 15 (3): 217-23, 2016.

19- O'HARE J.L., PARKIN D., VANDENBROECK C.P. and EARNSHAW J.J.: Midterm results of ultrasound guided foam sclerotherapy for complicated and uncomplicated varicose veins. European Journal of Vascular and Endovascular Surgery, 36 (1): 109-13, 2008.

20- ABD AL RAHMAN M., SALEM A., TAWFEK H. and ALBOUSHY A.: Comparative Study between Conventional Surgery \& Endovenous Radiofrequency Ablation in Management of Patients with Primary Varicose Veins. Zagazig University Medical Journal (ZUMJ): 19 (1): 10011, 2013.

21- WHITELEY M.S., SHIANGOLI I., DOS SANTOS S.J., DABBS E.B., FERNANDEZ-HART T.J. and HOLDSTOCK J.M.: Fifteen Year Results of Radiofrequency Ablation, Using VNUS Closure, for the Abolition of Truncal Venous Reflux in Patients with Varicose Veins. European Journal of Vascular and Endovascular Surgery, 54 (3): 357-62, 2017. 
22- KIANIFARD B., HOLDSTOCK J.M. and WHITELEY M.S.: Radiofrequency ablation (VNUS closure) does not cause neo-vascularization at the groin at one year: Results of a case controlled study. Surgeon, 4 (2): 71-4, 2006.

23- RUSTEMPASIC N., CVORAK A. and AGINCIC A.: Outcome of endovenous laser ablation of varicose veins. Acta Informatica Medica (AIM) (Journal of the Society for Medical Informatics of Bosnia \& Herzegovina); 22 (5): 329-32, 2014.

24- VELICKA L., KIEVISAS M. and KETURAKIS V.: A comparison of endovenous laser ablation and conventional surgery in patients with varicose veins of the lower limbs. Acta Angiologica, 21 (4): 107-15, 2015.

25- HIROKAWA M. and KURIHARA N.: Comparison of bare-tip and radial fiber in endovenous laser ablation with $1470 \mathrm{~nm}$ diode laser. Annals of Vascular Diseases, 7 (3): 239-45, 2014.

26- VOURLIOTAKIS G., SAHSAMANIS G., EVAGELIDIS P. and AIVATIDI C.: Endovascular laser treatment of incompetent saphenous veins using the $1470 \mathrm{~nm}$ diode laser and radial fiber. Annals of Medicine and Surgery, 25: 12-6, 2018.

27- COWPLAND C.A., CLEESE A.L. and WHITELEY M.S.: Factors affecting optimal linear endovenous energy density for endovenous laser ablation in incompetent lower limb truncal veins: A review of the clinical evidence. Phlebology, 32 (5): 299-306, 2016.

28- GOLBASI I., TURKAY C., ERBASAN O., KEMALOGLU C., SANLI S., TURKAY M. and BAYEZID Ö.: Endovenous laser with miniphlebectomy for treatment of varicose veins and effect of different levels of laser energy on recanalization: A single center experience. Lasers in medical science, 30 (1): 103-8, 2015.

29- ELBOUSHI A., ELSHERBENI M., GAMEEL A.M., SOROUR W., AMIN M., SAMIR A. and SALEM A.: The 1470 radial endovenous laser ablation of the great saphenous vein larger than $12 \mathrm{~mm}$ : Is it a good option?. A single center experience. Egyptian Journal of Surgery, 38 (1): 136-41, 2019.

30- MASSAKI A.B., KIRIPOLSKY M.G., DETWILER S.P. and GOLDMAN M.P.: Endoluminal laser delivery mode and wavelength effects on varicose veins in an ex vivo model. Lasers in surgery and medicine, 45 (2): 123-9, 2013.

31- KANSAKU R., SAKAKIBARA N., AMANO A., ENDO H., SHIMABUKURO T. and SUEISHI M.: Histological difference between pulsed wave laser and continuous wave laser in endovenous laser ablation. Phlebology, 30 (6): 429-34, 2015.

32- BRITTENDEN J., COTTON S.C., ELDERS A., TASSIE E., SCOTLAND G., RAMSAY C.R., NORRIE J., BURR J., FRANCIS J., WILEMAN S., CAMPBELL B., BA-
CHOO P., CHETTER I., GOUGH M., EARNSHAW J., LEES T., SCOTT J., BAKER S.A., MacLENNAN G., PRIOR M., BOLSOVER D. and CAMPBELL M.K.: Clinical effectiveness and cost-effectiveness of foam sclerotherapy, endovenous laser ablation and surgery for varicose veins: Results from the Comparison of Laser, surgery and foam Sclerotherapy (CLASS) Randomized controlled trial. In: Health Technology Assessment; 19 (27): 1-341, 2015.

33- NANDHRA S., EL-SHEIKHA J., CARRADICE D., WALLACE T., SOUROULLAS P., SAMUEL N., SMITH G. and CHETTER I.C.: A randomized clinical trial ofendovenous laser ablation versus conventional surgery forsmall saphenous varicose veins. Journal of Vascular Surgery, 61 (3): 741-6, 2015.

34- ROOPRAM A.D., LIND M.Y., VAN BRUSSEL J.P., TERLOUW-PUNT L.C., BIRNIE E., De SMET A.A. and Van Der HAM A.C.: Endovenous laser ablation versus conventional surgery in the treatment ofsmall saphenous vein incompetence. Journal of Vascular Surgery: Venous and Lymphatic Disorders, 1 (4): 357-63, 2013.

35- ASSER A.G. and SAAD R.G.: Ultrasonic guided foam sclerotherapy for varicose vein. Egypt Journal of Surgery, 32 (1): 12-9, 2013.

36- VARGHESE K., HUBERT N., THOMAS K.S., CHACKO S.A. and JOSE L.: Improvement in Venous Clinical Severity Score Following Ultrasound Guided Foam Sclerotherapy. Journal of Imaging and Interventional Radiology, 1 (1: 2): 1-4, 2017.

37- De OLIVEIRA R.G., FILHO D.M., ENGELHORN C.A., KESSLER I.M. and NETO F.C. (2018): Foam sclerotherapy for lower-limb varicose veins: Impact on saphenous vein diameter. Radiologia Brasileira, 51 (6): 372-6, 2018.

38- KALTEIS M., ADELSGRUBER P., MESSIE-WERNDL S., GANGL O. and BERGER I.: Fiveyear results of a randomized controlled trial comparinghigh ligation combined with endovenous laser ablation andstripping of the great saphenous vein. Dermatologic Surgery, 41 (5): 57986, 2015.

39- Van Der VELDEN S.K., LAWAETZ M., De MAESENEER M.G.R., HOLLESTEINA L., NIJSTEN T. and VAN DEN BOS R.R.: Predictors of Recanalization of the Great Saphenous Vein in Randomized Controlled Trials 1 Year After Endovenous Thermal Ablation. European Journal of Vascular and Endovascular Surgery, 52 (2): 234-41, 2016.

40- LATTIMER C.R., KALODIKI E., AZZAM M., MARKIS G.C., SOMIAYAJULU S. and GEROULAKOS G.: Interim results on abolishing reflux alongsidea randomized clinical trial on laser ablation with phlebectomiesversus foam sclerotherapy. International angiology: A journal of the International Union of Angiology, 32 (4): 394-403, 2013. 


\section{دراسة مقارنة بين العلاج بالرغوة المُصلبة بالقسطرة المُوجهَهة

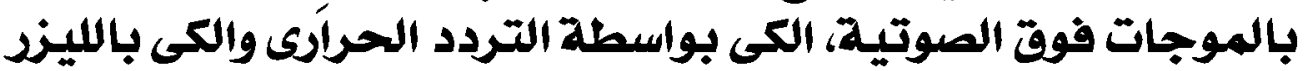

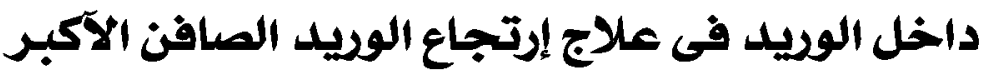

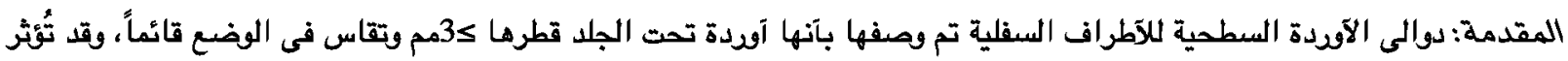
الدوالى على الآوردة السطحية الرئيسية، الوريد الصافن الآكبر، الوريد الصافن الآصغر آو آى روافد وريدية سطحية في الآطراف السفلية. وغالباً ما تتضمن الحالة إرتجاع فى الوريد الصافن الآكبر، وحتى وقت قريب كان العلاج الآمثل هو الريط العالى اللوريد مع نزعه وإستئصاله، وقد آدى ذلك لتصسين الآعراض وكذلك جودة المياة.

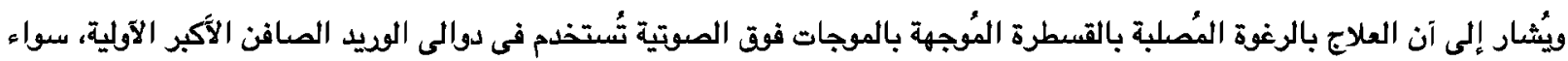

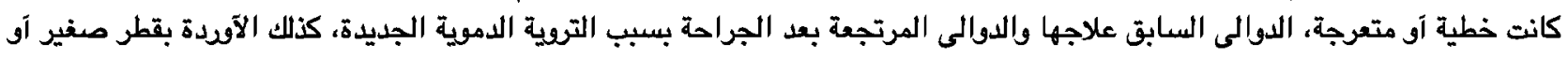

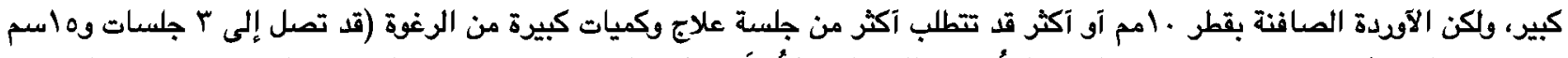

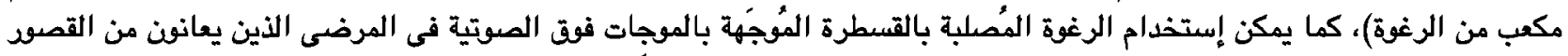

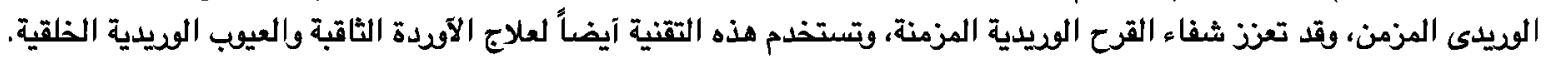

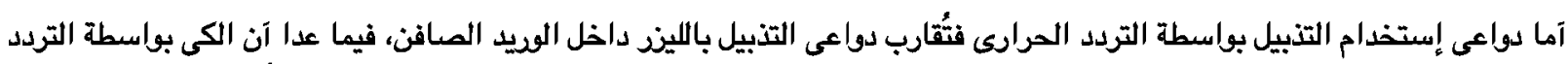

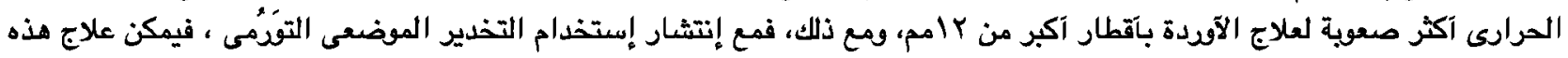

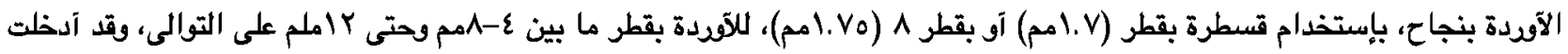

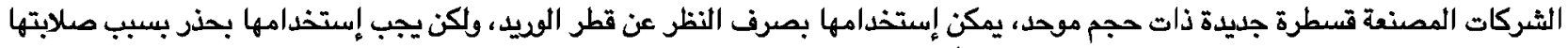
وحجمها، لتجنب ثقب الدوالى المتعرجة والصغيرة ذرة نسيباً.

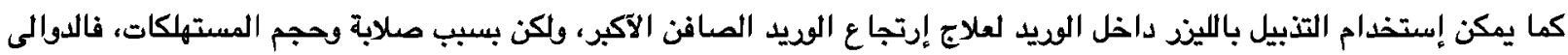

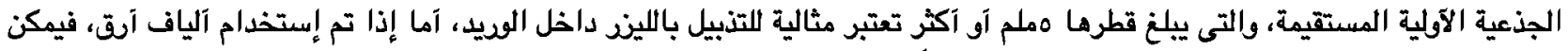

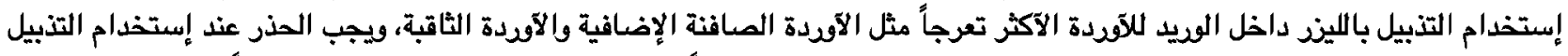

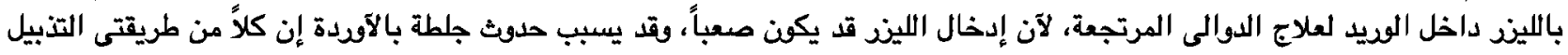

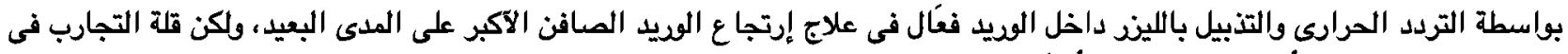

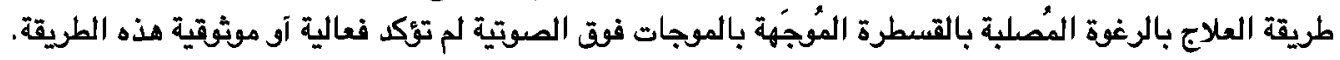

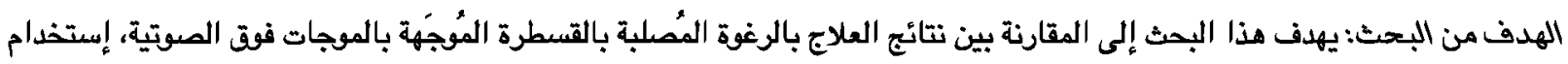

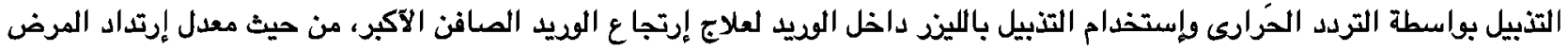

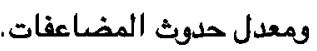

المواد وطرق البحث: آجريت مذه الدراسة بقسم جراحة الآوعية الدموية بمستشفيات جامعة الزتازيق المرضى الذين يعانون من دوالى بالآودرة السطحية للآطراف السفلية.

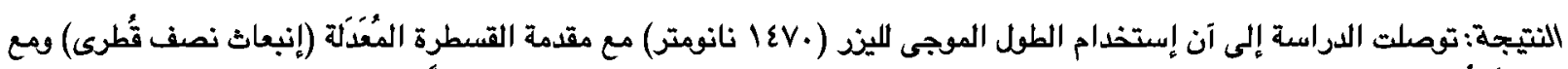

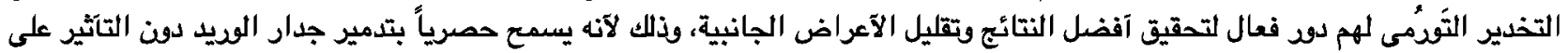

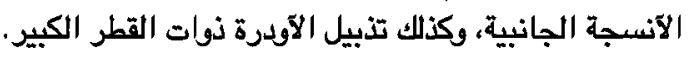

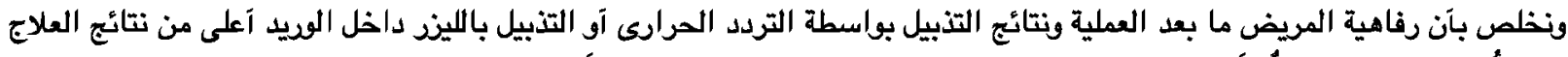

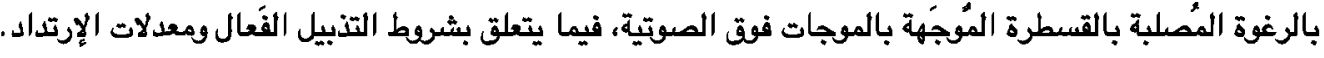

